\title{
El activo desactivado
}

Un lugar común de todo foro o seminario sobre gestión de empresas es afirmar que "las personas son el mayor activo de una organización". Una reciente encuesta sobre condiciones de trabajo y empleo no apoya esta visión.

Por Eduardo Abarzúa C.*

La legitimidad o "éxito" de un sistema se puede apreciar genera la actividad laboral, es decir, en la por la manera de responder a las expectativas de los actores sociales y por su capacidad para administrar el conflicto que naturalmente se genera por la diferencia CON RESPECTO a la participación en orde intereses.

Deto and nalmente sabemos con rescelización y también una muy baja tasa de trabajadores cubiertos por instrumentos colectivos de trabajo. Lo que queda son preguntas ¿Cómo se resuelven, entonces, las cotidianas diferencias entre trabajadores y jefes? ¿Cuál es el nivel de influencia que tienen los trabajadores en sus espacios de trabajo?, ¿Cuál es el nivel de tensión 0 antagonismo entre las partes?

Una reciente encuesta de la Dirección de Trabajo, el Ministerio de Salud y el Instituto de Seguridad Laboral (ex INP), permite tener una mirada a la calidad de nuestras las aspectos de la En particular, uno de os aspectos de la encuesta es el captulo nización de trabajadores. La temática refleja la capacidad de influir en la toma de decisiones en los espacios de trabaio que de producirse debiera impactar positivamente, por ejemplo, en la calidad de vida laboral, puesto que implica algún nivel de control sobre el cumplimiento de la ley y la prevención respecto de las condiciones de trabajo y empleo. Del mismo modo significa istribución del ingreso.

CON RESPECTO a la participación en orfirman lo sabido: es baja. Solo el $12,5 \%$ de la población encuestada dice pertenecer a stas organizaciones: 8,1\% señala adherir un sindicato y 3,1\% afirma ser parte de una asociación de funcionarios o colegio de lo que se asume, la encuesta revela una correlación entre el nivel educacional y la ciones: aumenta a medida que sube el nivel de educacion (un 26,6\% en aquellos con educacion universitaria completa). Una segunda dimensión es la toma de decisiones en el trabajo. El estudio identifio diferentes aspectos como salarios, horas de trabajo, vacaciones y descansos neras de resoner, as difego por las ma prámetros. En generat la gran y ijar los los encuestados tiene muy baja influencia en las decisiones: lo más común es la decisión unilateral de jefes o directivos (entre un $25,6 \%$ y $42,5 \%$ ). Sin embargo, se idenifican dos estrategias de influencia por parte de los trabajadores: la negociación un 10\% de la fuerza laboral y la presión dipertenencia o no a este tipo de organizacolectiva, que es utilizada entre un $0,6 \%$ y

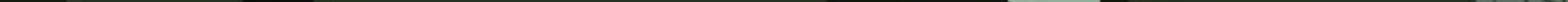


recta hacia los empleadores, utilizada entre un $0,6 \%$ a $3 \%$ de los casos. Un mecanismo
participativo como la consulta a los trabaparticipativo como la consulta a los traba-
jadores involucrados ocurre apenas para un rango entre el 14,3\% y 7,3\% de los encues tados, según sea el tema.

¿Y qué sucede con los trabajadores frente a crisis o dificultades económicas res señaresas? 60,5\% de los trabajadoenfrentada a hacer adecuaciones. Cuando han ocurrido, la fórmula ha sido principal-
mente el despido de trabajadores $(22,6 \%)$ el aumento de la producción con la mism cantidad de trabajadores $(13 \%)$, la contratación de trabajadores temporales (11.4\%) y la realización de nuevas tareas por part de los trabajadores $(10 \%)$

Finalmente, se midió la percepción de tensión social que tienen los trabajadores entre grupos sociales a nivel pais y en
la empresa. La mayor, a nivel pais, es, de

pobres (49,7\% de "mucha tensión" y $36 \%$

resultados muestran, a nivel empresa, que alrededor de un 40\% de los encuestados percibe "mucha tensión" y el 47\% "algo de tensión" entre empleadores y trabajadores.

LOS RESULTADOS SON INQUIETANTES. Existe baja injerencia de los trabajadores en las decisiones que afectan su entorno $y$ condiciones de trabajo $y$, cuando existen diferencias en la empresa, estas se resuelven a partir de la decision unilater de jefes o directivos. La expresión de difede trabajo tampoco es ejercida a través de instancias representativas: de alli que vivencia cotidiana no sea de diálogo y cooperación entre actores, sino más bien de confrontación o antagonismo. Los resultados cuantitativos no son mejores: el 60,80 de los trabajadores dice que gana menos $\$ 250.000$. El nivel de poder y el grado de participación equilibrado en los lugares de trabajo no solo promueven decisiones $m a$ justas, también son factores que hacen más competitivas y durables a las empresas, que mejoran la calidad de vida y la salud de

A pesar de estas cifras, un lugar común de todo foro o seminario sobre gestión de empresas es afirmar que "las personas son el mayor activo de una organización competitiva" Considerando los datos que entrega "a encuesta, una empresa que realmente logre implementar una estrategia de gestión innovadora en materia de relaciones laborales estará creando una ventaja competitiva durable a partir de un factor dificil de imitar: compromiso de los trabajadores y lealtad de la empresa para con su personal. Las relaciones laborales constituyen un sistema clave de la Gestión de Personas, y no solo a propósito de las los niveles de inflivas de trabajo, sino por los niveles de influencia y participación de ladas hace tiempo lo sabenilas desarroson mucho más competitivas cuando se gestionan en un ambiente de respeto, escucha, participación, confianza, creatividad innovación. Las compañias líderes de los paises desarrollados, y unas pocas en Chile, invierten fuerte en el desarrollo de relaciones de cooperación entre trabajadores, ejecutivos y representantes de los dueños. ¿Qué tan vigentes están los derechos democraticos en las empresas chilenas? E desafio es conciliar los derechos y deberes que una sociedad democratica entrega a sus ciudadanos con aquellos que se recodias en ae vien en la empresa. En estos en las posibilidades de ampial se ha centrado crática que ofrece nuestro sistomn democional, ¿por qué no añadir a esa discusión las posibilidades de profundización democrática que ofrecen nuestras instituciones y empresas? Después del hogar y antes que el barrio, las personas dedican su tiempo a trabajo y los negocios. La pregunta fundamental es cómo se construyen empresas donde se acepta y canaliza el debate y la egociación, donde se integra la maximización de su valor presente con la generación satisfacción laboral de las personas.
'Encuesta Nacional de Condiciones de Empleo, Trabajo y Salud, ENETS 2011. Fue aplicada desde septiembre de 2009 a octube entrevistadas en las 15 rer 9.500 personas muestra representa a más de siete millones de trabajadores.

\section{La difícil ruta del emprendimiento en la academia}

Por Alejandro Jiménez

"Profesor de Tecnologia e Innovación

Edion-in-Chef del Journal of Techno agy

Economia y Negocios, UAH

Recientemente el CONICYT, a través del eficiente a la hora de transferir resultados FONDEF, ha lanzado un concurso para de la investion

valorizar la investigación realizada en las merciales.

los resultados de la investigación cientifica Un aspecto interesant nerT ras a investigado$\begin{array}{ll}\text { a nuevos negocios: asociar a memoristas } & \text { res vinculados a proyectos FONDECYT: la } \\ \text { de pre o postgrado con profesores vincu- } & \text { cuna y nata de casi todas las publicaciones }\end{array}$ de pre o postgrado con profesores vincu- cuna y nata de casi todas las publicaciones lados a proyectos FONDECYT. La idea es relevantes que produce la comunidad cienapoyar a los estudiantes en la materializados de investigaciones realizades en tesis. ifica en revistas de corriente principal. Por ca transferir y crear negocios a partir de la mejor investigación realizada en el país. Desafortunadamente, en Chile no existe una cultura del emprendimiento dentro de nuevos modelos de asociación que favoLa iniriva moulsada por el CONICYT relevante y positiva ya que apunta a generar emprendimientos de base cientifica en lo que respecta a emprender negocios. Dentro del ambito académico, es normal la a al alo de discín usas cono la ingeniena o tinoemérica- la investigión culadas a las ciencias b́́sicas, como la biologia fisica y ciencias de la vida. La razon es muy simple: la comunidad cientific no sabe hacer negocios; sabe hacer buen paises desarrollados el escenario es opuesto: los privados tienen un rol protagónico ciencia. Por lo tanto, no se le puede pedir a ella patrocinar proyectos estudiantiles que apuntan más bien a materializar pro
o servicios con valor de mercado.

investigación cientifica y tecnologica tien la legishoín permite a las misarial, y Además, en Chile no existe una instituciopatentar como propias las investigaciones nalidad dentro de las universidades cientifinanciadas con fondos federales lo que fico-tecnológices que permita traferi los favorece el ingreso de privados interesados resultados de la investigación básica a procado. Esto ha impulsado la colaboración algo de suerte- algunas pocas universidaentre la institucionalidad pathe dentro de sus planteles. Sin embargo, ha sido muchas veces la improvisación la surgen de la apropiación del conocimien entifico.

Una propuesta destinada a robustecer

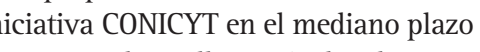

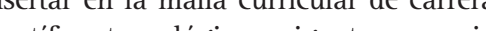
as al emprendimiento, los negocios y ropiedad intelectual. Es importante que as nuevas generaciones de investigadolos aspectos que regulan la propiedad de conocimiento y los resultados de la inves-

Ua generar instrumentos que permitan a las

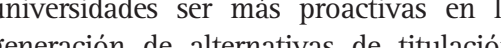
egreso de sus estudiantes. Las tesis de rado, con el clásico esquema de introducción, materiales y métodos, resultados y conclusiones, funcionan para los interesados en seguir el camino de la ciencia, pero no para los emprendedores que quiere aterializar sus conocimientos medianbuen plan de negocios.

Económico \}

Fono Facultue Rodriguez Grossi.

e-mail: jrodrisu@ 8366

economiaynegocios unhurtado.cllobservatorio Producción OE: Comunicar, Escuela 